\title{
Marine benthic faunal activity patterns on a sediment surface assessed by video numerical tracking
}

\author{
Jean-Claude Duchêne ${ }^{1, *}$, Rutger Rosenberg ${ }^{2}$ \\ ${ }^{1}$ Observatoire Océanologique de Banyuls, BP 44, 66651 Banyuls sur-Mer, France \\ ${ }^{2}$ Department of Marine Ecology, Göteborg University, Kristineberg Marine Research Station, 45034 Fiskebäckskil, Sweden
}

\begin{abstract}
Most marine benthic macrofaunal species are buried in the sediment but feed on the sediment surface. We measured benthic faunal activity on the sediment surface in $0.25 \mathrm{~m}^{2}$ box-cores from a $75 \mathrm{~m}$ depth in a Swedish fjord. The techniques used were video numeric tracking and electronic intelligent sensors, where the activity pattern was continuously recorded. During a $4 \mathrm{~h}$ recording, $24 \%$ of the examined surface area showed infaunal activity. When phytodetritus was added to the same surfaces, the areas searched by the fauna almost doubled over the next $4 \mathrm{~h}$. Thus, the main part of the sediment surface is most probably covered daily by infaunal activity, particularly when food is available. Arms of Amphiura filiformis and A. chiajei contributed to $40-80 \%$ of the total surface area covered by faunal activity, which was $>15$ times that of tentaculate feeding activity of Melinna cristata. Time frequency recordings showed that the response of the Amphiura species to food supply was strong during the first $25 \mathrm{~min}$, followed by a decline, which probably was related to processing and storage of food in the sediment.
\end{abstract}

KEY WORDS: Amphiura $\cdot$ Melinna $\cdot$ Video analysis $\cdot$ Actography $\cdot$ Food supply $\cdot$ Foraging

Resale or republication not permitted without written consent of the publisher

\section{INTRODUCTION}

Marine sediments harbour a diverse benthic fauna, where bioturbation and feeding activities can be intense and the surficial sediment is repeatedly reworked (Rhoads 1974). Many species are buried in the sediment for protection against predators. To collect food particles at the sediment-water interface they may use tentacles (e.g. polychaetes), siphons (bivalves) or arms (brittle stars). Some of these animals are filter feeders and collect suspended food particles from the water above the bottom (Riisgård \& Larsen 2000). Others are deposit feeders that are generally specialised in collecting particles from the sediment surface or within the sediment (Jumars \& Wheatcroft 1989). Infaunal species may construct tubes or burrows to facilitate feeding and oxygenation of their microenvironment, or they may simply move through the sediment in a bulldozing mode like sea urchins (Fauchald

*E-mail: duchene@obs-banyuls.fr
\& Jumars 1979, Pearson \& Rosenberg 1987). Sediment reworking rates have been summarised to be significant in many infaunal species (Diaz \& Schaffner 1990). Depth of bioturbation in the sediment varies between habitats and with species composition but can extend down to depths of $20 \mathrm{~cm}$ or more (Dauwe et al. 1998).

Benthic species compete for the episodic input of nutritious food, and to be successful they may have to search the sediment surface more or less continuously or have sensors that can detect recently settled organic matter. Despite a high animal activity on the sediment surface, the activity pattern has never been recorded and quantified in a natural sedimentary habitat. In this study we present new information about the activity of benthic animals at the sediment-water interface and their response to food supply. The faunal activity was recorded in $0.25 \mathrm{~m}^{2}$ Plexiglas boxes with natural sediment and fauna from a $75 \mathrm{~m}$ depth of a Swedish fjord. The techniques used were real-time video tracking and electronic intelligent sensors where the activity pattern was continuously recorded over several hours at a time. 


\section{MATERIAL AND METHODS}

Sediment with intact fauna was collected from a $75 \mathrm{~m}$ depth $\left(58^{\circ} 22.7^{\prime} \mathrm{N}, 11^{\circ} 36.3^{\prime} \mathrm{E}\right)$ in the Gullmarsfjord on the Swedish west coast. The sampler was a USNEL spade-corer (700 kg) (Rosfelder \& Marshall 1967), where transparent plexiglas boxes $(47 \times 47 \mathrm{~cm}$, height $39 \mathrm{~cm}$ ) were installed inside the corer before each deployment. Ten boxes were collected on 6 March 2000. Each box was closed on the bottom on board the boat and transported to Kristineberg Marine Research Station nearby. The sediment was $\sim 30 \mathrm{~cm}$ high with $\sim 15 \mathrm{~cm}$ of seawater above the sediment. The boxes were put in a room with a constant temperature of $8^{\circ} \mathrm{C}$, and each box was continuously flushed with 2 1 filtered (1 mm meshes) seawater $\mathrm{min}^{-1}$ of $34 \mathrm{psu}$, i.e., similar to natural conditions. The animals in the boxes were acclimated $3 \mathrm{wk}$ until the start of the experiment on 27 March. The macrofaunal (>1 mm) composition at the sampling site was analysed by taking three $0.1 \mathrm{~m}^{2}$ Smith-McIntyre grab samples in April 2000.

Samples of the top 0 to $1 \mathrm{~cm}$ of the sediment in 3 boxes ( 3 replicates in each) were freeze-dried, and nitrogen and total carbon were analysed with an NA 1500 NC analyser (Fisons, Milano). Food was added to 3 of the boxes as marine microalgae cryopaste (Chaetoceros gracilis and C. muellari, cryopreserved). A mix of $1 \mathrm{ml}$ algae paste and $1 \mathrm{ml}$ seawater was spread evenly on the sediment surface covered by the video system by using a pipette. As for the sediment, the algae paste was analysed for nitrogen and carbon and contained on average $( \pm \mathrm{SE}) 5.2 \pm 0.06 \%$ nitrogen and $32.6 \pm$ $1.8 \%$ carbon.

The activity of the benthic fauna was recorded by means of an actographic device composed of an intelligent Coupled Charged Device (CCD) camera loaded with image analysis programmes in permanent memory, connected to a desk computer (Duchêne \& Nozais 1994, Nozais et al. 1997, Jordana et al. 2000). This computer was running an interface programme to store the numeric results sent by the sensor. The sensor was placed at a $60 \mathrm{~cm}$ distance above the sediment and recorded the activity of a $153 \times 117 \mathrm{~mm}$ surface. A set of data was collected every $3 \mathrm{~s}$. Real-time analysis resulted in a batch of numeric objects describing the movements detected on the surface, which were sent to the desktop computer and stored. Connecting a video monitor on a dedicated output of the sensor allowed us to visualise the recorded sediment surface. Alteration between original video images and computed numeric objects allowed us to visually estimate the sediment area affected by movement. Collection of image files in a Joint Photography Experts Group (JPEG) format allowed comparison of the changes of activities with location, and identification, when pos- sible, of the species corresponding to the recorded activities. The sensor had a resolution of $744 \times 568$ pixels, corresponding to a resolution of $0.2 \mathrm{~mm}$ on the sediment surface when the $15 \mathrm{~mm}$ lens is used. This is supposed to be sufficient to detect most of the macrofaunal activity. The cumulative total area covered by the active animals was measured between 7 and $15 \mathrm{~h}$ in 10 replicate boxes. The programme scanned every image of the files and every time a new activity was detected on the surface it was graphically added to give the total sediment surface activity. When an activity on a given position was detected several times it was recorded as only 1 point of activity. This quantified newly exploited surface areas over time. This gave an asymptotic curve representative of the actual infauna activity at the water-sediment interface.

Numeric data were also analysed to separate activities of different animals. This resulted in numeric tracks over time for species easily recognisable at the sediment surface. When it was impossible to attribute an activity to a species, values were added to an 'unknown' column. Species activity was then reconstructed by adding every specific individual activity in every image. This allowed us to obtain the activity of a target species.

\section{RESULTS}

The 10 dominant benthic species collected in April 2000 in the Gullmarsfjord are listed in Table 1. The total number of species in the 3 grab samples was 53 . The composition at these samples, collected of the same site, should have corresponded approximately to that in the boxes used in the activity analysis. Most of

Table 1. The 10 dominant benthic species found at $75 \mathrm{~m}$ in the Gullmarsfjord in April 2000. Biomass is in grams (ethanol weight). Numbers and biomass are per $0.1 \mathrm{~m}^{2}( \pm \mathrm{SE})$. Feeding mode is indicated as surface deposit feeding (SD), subsurface deposit feeding (SSD) and suspension feeding (SF)

\begin{tabular}{|lrcc|}
\hline Species & Abundance & Biomass & $\begin{array}{c}\text { Feeding } \\
\text { type }\end{array}$ \\
\hline Abra nitida & $29 \pm 5.4$ & $1.3 \pm 0.1$ & SD \\
Amphiura filiformis & $24 \pm 6.6$ & $2.9 \pm 1.2$ & SD/SF \\
Mysella bidentata & $19 \pm 2.7$ & $0.1 \pm 0.0$ & SF \\
Heteromasus filiformis & $19 \pm 6.2$ & $0.1 \pm 0.0$ & SSD \\
Spiophanes kroeyeri & $18 \pm 2.8$ & $0.4 \pm 0.0$ & SD \\
Scalibregma inflatum & $16 \pm 6.8$ & $0.7 \pm 0.3$ & SSD \\
Thyasira equalis & $14 \pm 5.4$ & $0.2 \pm 0.2$ & SSD \\
Myriochele oculata & $12 \pm 4.3$ & $1.2 \pm 0.1$ & SF \\
Melinna cristata & $11 \pm 3.8$ & $2.0 \pm 0.2$ & SD \\
Anobothrus gracilis & $10 \pm 3.7$ & $0.4 \pm 0.2$ & SD \\
Total community & $266 \pm 48$ & $29.0 \pm 4.6$ & \\
& & & \\
\hline
\end{tabular}


the species were either surface deposit feeders or subsurface deposit feeders. One of the dominant species, Amphiura filiformis, can be a suspension feeder (Loo et al. 1996) but can also feed efficiently on the sediment surface (Rosenberg et al. 1997). The mean number of $A$. chiajei per $0.1 \mathrm{~m}^{2}$ was $9 \pm 1.7$.

On visual observations of the boxes we frequently saw arms of the brittle stars Amphiura filiformis and A. chiajei sweeping the sediment surface, the polychaete Melinna cristata showing its tentacles outside the tube at irregular intervals, episodic movements of the polychaete Ophiodromus flexuosus on the surface and at times disappearing into burrows, and the bivalve Chlamys septemradiata (= Pseudamussium septemradiatum) filtering water while attached to different objects, e.g. tubes of Euchone papillosa, which was filter-feeding with its crown of tentacles. The 2 Amphiura species were recorded in the grab samples, but their arms could not be separated into species in the images. The only larger species with a mean biomass $>1 \mathrm{~g}$ wet weight per $0.1 \mathrm{~m}^{2}$, in addition to those listed in Table
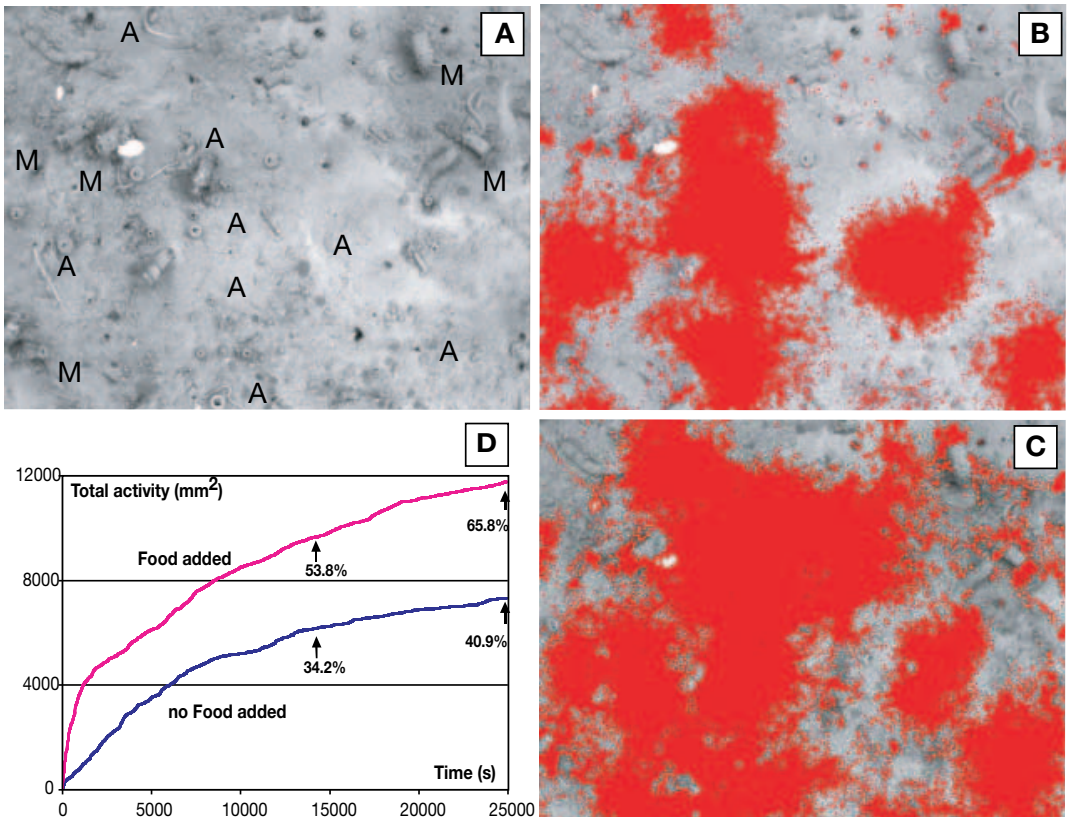

Fig. 1. Measurements of total activity at sediment-water interface. (A) Image $(153 \times 117 \mathrm{~mm})$ of the sediment surface. A: Amphiura spp.; M: Melinna cristata. (B) Records of activity during $7 \mathrm{~h}$ before food addition (red surface shows areas of benthic activity). (C) Records of activity after food addition on the sediment surface. (D) Records of the total activity in $\mathrm{mm}^{2}$ on the sediment without food and after food addition. Activity on sediment surface was recorded every $3 \mathrm{~s}$. Arrows indicate values for 4 and $7 \mathrm{~h}$

1, were the heart urchins Brissopsis lyrifera, Echinocardium cordatum and E. fla-

vescens. These sea urchins were occasionally seen bulldozing within the sediment in the boxes. The contents of nitrogen and total carbon in the sediment surface were $0.3 \pm 0.004$ and $4.0 \pm 0.15 \%$ of the dry weight, respectively.

\section{Total benthic activity}

A view of a sediment surface is shown in Fig. 1A. Most of the tubes belonged to Melinna cristata, but all were not active or inhabited. Some arms of Amphiura filiformis or A. chiajei were also seen in a horizontal position on the sediment surface. The area where activity was registered over $7 \mathrm{~h}$ is indicated in Fig. 1B. After $4 \mathrm{~h}$ it covered $34 \%$ of the total area. After $7 \mathrm{~h}$ it reached $41 \%$ of that surface. In longer recordings (4 replicates, $15 \mathrm{~h}$ ) activity covered $54.4 \pm 7.4 \%$ (SE) of the total area. Most of the movements were caused by Amphiura arms; we observed 8 arms in Fig. 1B. The activity of $M$. cristata covered a much smaller area close to the tube opening as indicated in the upper right corner of the image. The number of active M. cristata was 6 . After food was added to the same patch of sediment, the area of animal activity increased significantly (Fig. 1C). Now the activity covered $54 \%$ of the total area after $4 \mathrm{~h}$ and $66 \%$ after $7 \mathrm{~h}$. No new active animals were detected. The response of the animals to food supply was immediate (Fig. 1D). The cumulative area of sediment sur-

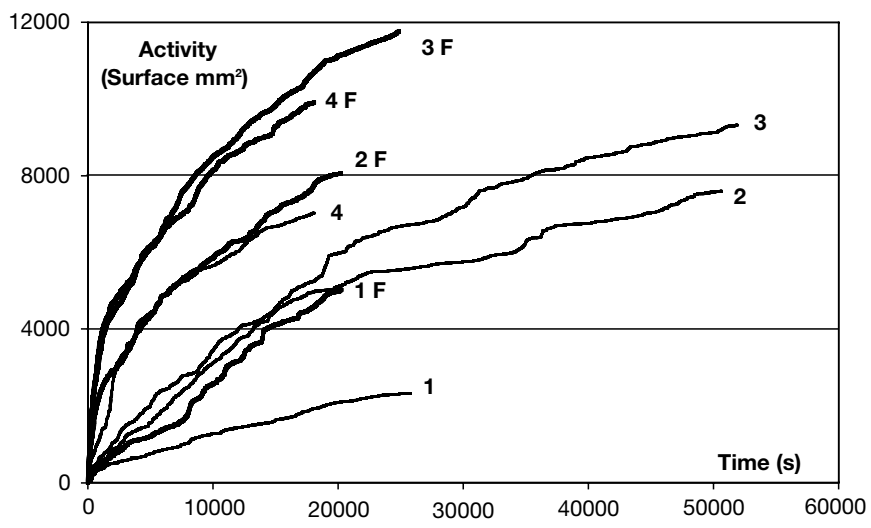

Fig. 2. Animal activity on sediment surface (in $\mathrm{mm}^{2}$ ) with and without food in 4 different box-cores. The same area $(153 \times$ $117 \mathrm{~mm}$ ) of the sediment was observed before and after food was supplied (F). Number indicates replicate. Addition of food was followed immediately by a significant increase in total activity 


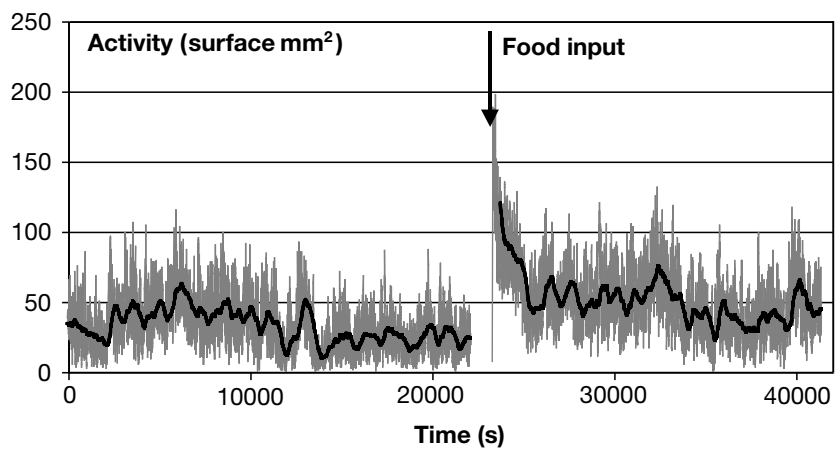

Fig. 3. Time frequency activity pattern of total fauna on the sediment surface continuously recorded for about $7 \mathrm{~h}$ before and $6 \mathrm{~h}$ after food was supplied (arrow) to the same observed area. The moving average on 144 images is shown

face covered by the animal activity was much higher with food than without and the difference increased over the $7 \mathrm{~h}$ of recording.

The cumulative activity pattern before and after food addition is presented in Fig. 2. The activity was different between replicates, but the response to food was rapid in all experiments. Four hours after food was added, the cumulative area searched was $1.93 \pm 0.57$ (SE) times greater than for the same time period without food. In total, $24.0 \pm 12.4$ to $41.5 \pm 14.2 \%$ of the total observed area was covered during this time by animal activity. Naturally, the magnitude of activity was dependent on numbers and species composition in the observed area.
Species living beneath the sediment surface and occasionally appearing at the sediment interface were detected as unknown patterns and added to the general background faunal activity of the sediment studied. Patterns of activity created by mobile species such as Ophiodromus flexuosus were detected and recorded. Replicate 1 (Fig. 2) had a low density with only 2 arms of Amphiura spp. Nine M. cristata were active. This gave, however, a rather low total activity. When food was added there was no steep increase during the first minutes. Replicate 2 was another benthic assemblage, where 7 Amphiura spp. arms provided a high activity (24\% of total activity without and $39 \%$ with food addition after $4 \mathrm{~h}$ ). A terebellid worm extended its tentacles into the site of observation during the period without food. Three O. flexuosus were moving across the surface. When food was added, a rapid increase was noted in Amphiura activity and a reduction in the extension of the terebellid tentacles. The activity of $O$. flexuosus was low with only 2 tracks visible. Replicate 3 was a mixture of active Amphiura spp. and M. cristata with a high activity ( $24 \%$ of total activity without and $54 \%$ with food addition after $4 \mathrm{~h}$ ). Food addition induced a steep initial increase related to Amphiura spp. activity. Replicate 4 was characterised by a large number of Amphiura spp. arms (16 detected) providing a large activity both without and with food (39\% of total activity without and $50 \%$ with food addition after $4 \mathrm{~h}$, with a significant effect, $\mathrm{p}<0.001$ ). Four $M$. cristata tubes were active. A fast response to food addition resulted in a steep initial part of the curve. This was

Table 2. Relative hourly activities as a percentage of total activity of Amphiura filiformis and A. chiajei combined and of Melinna cristata before and after food addition. Activity during the first $25 \mathrm{~min}$ after food was supplied is also indicated. Mean column gives the mean value of the 1200 activity records collected every hour in $\mathrm{mm}^{2}$

\begin{tabular}{|c|c|c|c|c|c|c|c|c|}
\hline \multirow[t]{2}{*}{ Time (h) } & \multicolumn{3}{|c|}{ Amphiura filiformis } & \multicolumn{3}{|c|}{ Melinna cristata } & \multicolumn{2}{|c|}{ Total activity } \\
\hline & Mean & $\mathrm{SD}$ & $\%$ & Mean & $\mathrm{SD}$ & $\%$ & Mean & $\mathrm{SD}$ \\
\hline-7 & 9.04 & 10.74 & 70.7 & 0.19 & 0.92 & 1.5 & 12.79 & 11.45 \\
\hline-6 & 18.69 & 15.50 & 78.6 & 0.14 & 0.26 & 0.6 & 23.79 & 16.43 \\
\hline-5 & 17.92 & 13.18 & 80.8 & 0.21 & 0.64 & 0.9 & 22.17 & 14.59 \\
\hline-4 & 8.81 & 11.39 & 76.9 & 0.15 & 0.33 & 1.3 & 11.46 & 12.88 \\
\hline-3 & 2.80 & 4.45 & 40.7 & 0.33 & 0.52 & 4.7 & 6.88 & 5.72 \\
\hline-2 & 3.09 & 4.58 & 47.7 & 0.40 & 0.51 & 6.2 & 6.48 & 5.85 \\
\hline-1 & 5.65 & 5.30 & 79.6 & 0.27 & 0.34 & 3.8 & 7.09 & 5.56 \\
\hline Mean & 9.43 & & 67.9 & 0.24 & & 2.7 & 12.95 & \\
\hline \multicolumn{9}{|c|}{ Food addition } \\
\hline $25 \min$ & 34.05 & 13.95 & 83.0 & 0.52 & 1.22 & 1.3 & 41.03 & 13.87 \\
\hline 1 & 21.99 & 15.03 & 78.9 & 0.59 & 1.16 & 2.1 & 27.87 & 16.08 \\
\hline 2 & 12.35 & 8.24 & 73.6 & 0.30 & 1.34 & 1.8 & 16.76 & 8.81 \\
\hline 3 & 11.71 & 8.03 & 69.4 & 0.33 & 0.95 & 1.9 & 16.86 & 9.16 \\
\hline 4 & 7.31 & 6.57 & 67.9 & 0.33 & 1.35 & 3.0 & 10.77 & 7.41 \\
\hline 5 & 7.36 & 7.19 & 54.0 & 0.32 & 1.90 & 2.3 & 13.63 & 9.69 \\
\hline 6 & 4.91 & 2.51 & 63.3 & 0.39 & 0.78 & 5.0 & 7.75 & 2.84 \\
\hline Mean & 10.94 & & 67.9 & 0.38 & & 2.7 & 15.61 & \\
\hline
\end{tabular}


related to Amphiura spp. food gathering responsible for up to $90 \%$ of the total activity in the first minutes.

Analysis of time frequency activity of all animals on the sediment surface is shown in Fig. 3. Before food was added, the activity was variable with some periodic activity, which probably mirrors periods of search for food and periods of rest. When food was supplied, the searched area initially increased by about 5 times, and a higher activity $(\mathrm{p}<0.001)$ was maintained for at least $60 \mathrm{~min}$.

\section{Activity of Amphiura spp. and Melinna cristata}

From the appearances in the images, it was possible to quantify the activities of Amphiura filiformis and $A$. chiajei combined, and of Melinna cristata. The relative activities, which are expressed as the percentage of total activity, are presented as hourly means in Table 2. The activity of the Amphiura species contributed 40 to $80 \%$ of total activity. The activity measured as area covered was at least 15 times greater for Amphiura spp. than for $M$. cristata. (Table 2).

Graphs of the cumulative activity and time frequency activity of Amphiura spp. and Melinna cristata are shown in Fig. 4. The pattern of time frequency activity of the Amphiura species (Fig. 4B) was similar to that of the total activity. The response to food supply was very strong during the first 25 min contributing $83 \%$ of the total (Table 2). After that a steep decrease was recorded followed by a secondary increase. The activity of $M$. cristata increased after food was supplied (Fig. 4C), but this was not as rapid as for Amphiura spp. The activity pattern was erratic compared with that of Amphiura spp. When several individual $M$. cristata were feeding simultaneously it showed up as a high peak of short duration extending for 3 to $6 \mathrm{~s}$.

Besides Amphiura spp. and Melinna cristata other animals were also active on the sediment surface, but some of these were not identified in the images. Among those species excluded from measurements of individual activity were Ophiodromus flexuosus (a species that often came in and out of the video field), Abra nitida and Spiophanes kroeyeri (where activity was due to defecation as seen in the video recordings).

\section{DISCUSSION}

In this study we introduced a new technique to measure activity of benthic animals on a sediment surface. In the experimental set-up, we used box-cores in a laboratory system that allows most benthic animals to survive for several months (Berge et al. 1986). Their activity is assumed to be close to that in nature as they were
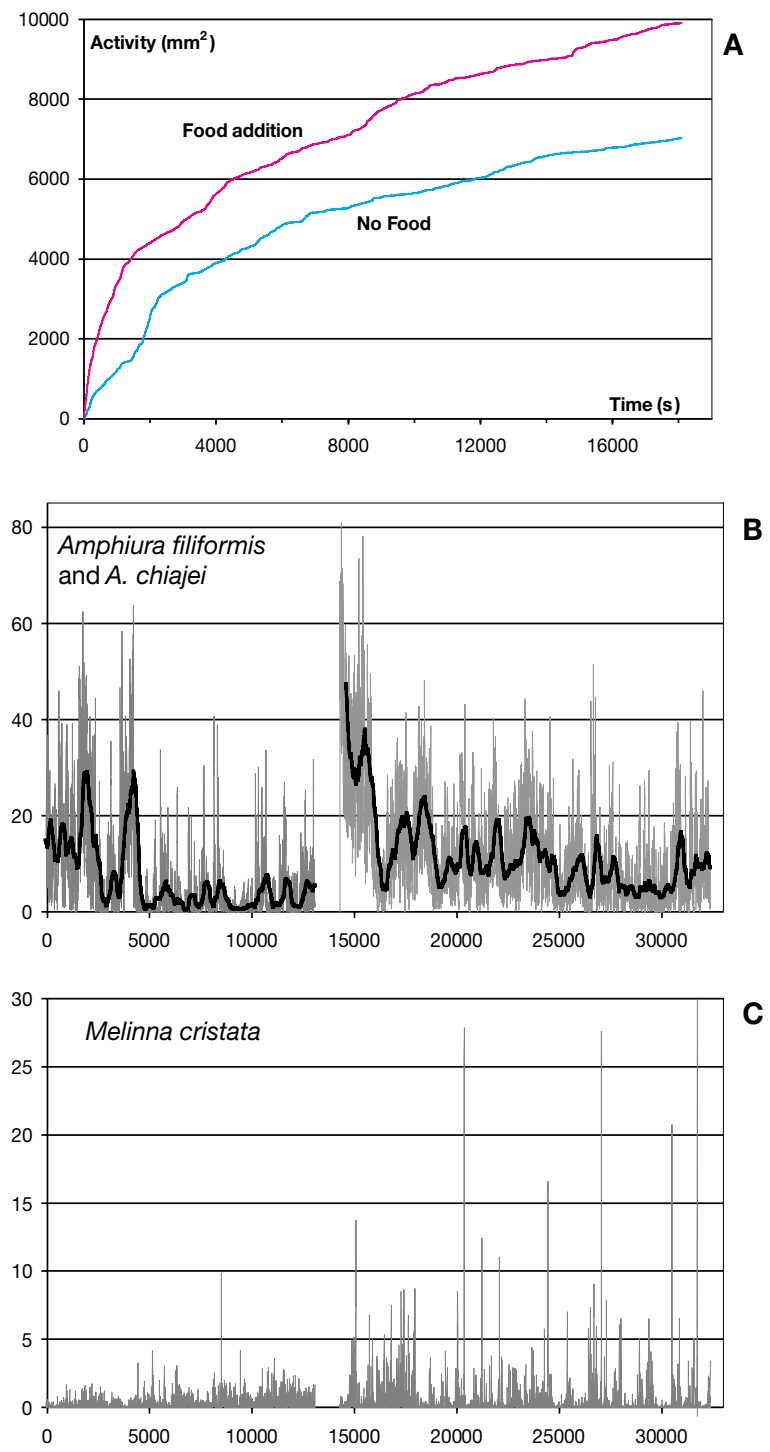

Fig. 4. (A) Total cumulative activity and (B) time frequency activity of Amphiura filiformis and A. chiajei and (C) of Melinna cristata on a sediment surface before and after food addition

collected together with the sediment, and salinity and water temperature were similar to that of their natural habitat. The electronic intelligent sensors detected movements of particles or of animal appendages at distances of only $0.2 \mathrm{~mm}$. This means that most movements of macrofauna and possibly of meiofauna would be recorded. The records included digitised pictures of the sediment. This allowed us to detect changes in the position of a particular individual. However, the activity of subsurface deposit feeders at intervals also shows signals at the surface. Among the dominants in the studied community, only Scalibregma inflatum might have had a high activity in the sediment. The sea 
urchins contributed negligibly to the activity as they rarely appeared in the area where recordings were made. Thus, the main activity recorded in this study must have been due to animals moving on the sediment surface. As the technique records only the sediment surface, the activity of several non-observed species inside the sediment was underestimated.

The curves of total activity presented in Fig. 2 are saturation-like curves. They reached an asymptote, and combined to a spatial expansion rate that is specific of the density and activity on the observed sediment. Over time some animals are likely to change their position in the sediment to be able to explore other parts of the sediment. Consequently, the curve would not reach an asymptote, but rather increase slowly as individual animals move inside the sediment. This movement was visible in the longer recordings: on a sediment without food addition the activity covered an average of $41 \%$ of the total surface after $7 \mathrm{~h}$ and $54 \%$ after $15 \mathrm{~h}$. Species living in tubes, such as $\mathrm{Me}$ linna cristata, remained in their position. In contrast, motile species such as Bryssopsis lyrifera and Amphiura filiformis moved in slow motion. When the activity curve becomes rather linear, its slope is related to the number of animals exploring new sections of the sediment. A dynamic survey of the sediment must take those moving phases into consideration. The continuous numeric recording with records of an image from time to time allows control of spatial position of the animals as well as a time frequency analysis of the activity patterns. Thus, a minimum time is required to get information on the dynamics of the sediment analysed. This may be appreciated by observation of the dynamics of the response of the benthic assemblage. In this study a time of $4 \mathrm{~h}$ was appropriate to obtain good estimates of activity, which was selected after 5 trials with $15 \mathrm{~h}$ recordings.

Records of the activity show that there was an overlap of the areas exploited by some species. The activity of benthic animals may be a result of search for food or territorial behaviour (Levin 1981). In the present study it was shown that part of the sediment surface was continuously searched even when no or little particulate food settled on the bottom. This was visible from individual activity patterns extracted from the cumulated signal. Competition evolves when 2 species seek the same food resource, especially if food is limited. Thus, species try to spread out to optimise feeding conditions, which have been shown for Amphiura filiformis (Rosenberg et al. 1997). This is also illustrated for Amphiura spp. in this study (Fig. 1B), where their arms searched the bottom in a circle with the arms protruding from the sediment in the centre. A. filiformis seems to have 2 arms active at the sediment surface (Loo et al. 1996). Given that A. filiformis was about 2.7 times more abundant than $A$. chiajei, most of their combined activity can probably be attributed to A. filiformis. The presence of Melinna cristata tubes may be a hindrance for that circular activity, as shown on the left side of Fig. 1B close to the white shell. When animals are closely situated, they may disturb each other by antagonistic behaviour. Intraspecific aggressive behaviour has been shown for, e.g., the spionid Pseudopolydora paucibranchiata (Levin 1981) and for A. filiformis (Rosenberg et al. 1997). Such disturbance may induce changed activity patterns both within and between species.

The water supplying the experiments was pumped from a $35 \mathrm{~m}$ depth through $1 \mathrm{~mm}$ filters, which probably resulted in negligible particulate food in the food supply. When food was added to the box-cores, animal activity was concentrated in the same areas that were searched before. This activity pattern suggests that it may be an advantage to be active when food suddenly appears on the sediment. Particularly the Amphiura species were active, and when food appeared they cleared the surface from the visible green phytodetritus within minutes. As seen in Fig. 4 and Table 2, Amphiura spp. were very active for about $25 \mathrm{~min}$ after food had been added, but after that period the activity declined to a low level. This decline in activity was lower than the total activity (Fig. 3), indicating that species other than Amphiura spp. were active at that time. The behaviour of the Amphiura species suggests that they remove food from the surface that cannot be ingested immediately and probably process that food in the sediment. Thus, that excess food may be stored within the sediment for later use. Food detection was sometimes followed by displacement of the burrow openings to improve food collection, which was observed in the video recordings. A similar behaviour of subsurface feeders to drag down food from the surface has been reported by Blair (1996) and Levin et al. (1997). Melinna cristata did not respond immediately to the food supply and can probably not record a sudden change in food availability. However, when the food was found, the feeding activity increased and was maintained at a level higher than before food was added.

The mean sediment surface area covered by infaunal activity over $4 \mathrm{~h}$ recordings was $24 \%$ and when food was added $41 \%$ (Fig. 2). Thus, the benthic animals were active over a large area for a few hours only. Many of the species recorded here have been classified as sessile or weakly mobile. However, the probably most active species in this study, Amphiura filiformis, has been shown to be able to move more or less continuously within the sediment (Rosenberg et al. 1997). Thus, the areas where no activity was recorded in this study would most probably have shown animal 
activity within the next hours, particularly if food were still available. Consequently, the length of recording animal activity is crucial for the results. In benthic communities with a species composition similar to the one studied here, it is likely that most of the sediment surface may be used for animal activity every $24 \mathrm{~h}$ and most parts much more frequently.

\section{LITERATURE CITED}

Berge JA, Schaanning M, Bakke T, Sandøy KA, Skeie GM, Ambrose WG (1986) A soft-bottom sublittoral mesocosm by the Oslofjord: description, performance and examples of application. Ophelia 26:37-54

Blair NE (1996) The short-term fate of fresh algal carbon in continental slope sediments. Limnol Oceanogr 41:1208-1219

Dauwe B, Herman PMJ, Heip CHR (1998) Community structure and bioturbation potential of macrofauna at four North Sea stations with contrasting food supply. Mar Ecol Prog Ser 173:67-83

Diaz RJ, Schaffner LC (1990) The functional role of estuarine benthos. In: Hairem M, Krome EC (eds) Perspectives on the Chesapeake Bay, 1990. Advances in estuarine sciences. Chesapeake Research Consortium, Gloucester, p 25-56

Duchêne JC, Nozais C (1994) Light influence on larval emission and vertical swimming in the terebellid worm Eupolymnia nebulosa (Montagu, 1818). In: Dauvin JC, Laubier L, Reish DJ (eds) Acts of 4th International Polychaete Conference. Mèmoires du Museum National d'Histoire Naturelle, Paris, p 405-412

Fauchald K, Jumars P (1979) The diet of worms; a study of polychaete feeding guilds. Oceanogr Mar Biol Annu Rev 17:193-284

Jordana E, Duchêne JC, Charles F, Grémare A, Amouroux JM (2000) Experimental study of suspension-feeding activity in the serpulid polychaete Ditrupa arietina (OF Müller). J Exp Mar Biol Ecol 252:57-74

Editorial responsibility: Otto Kinne (Editor), Oldendorf/Luhe, Germany
Jumars PA, Wheatcroft RA (1989) Responses of benthos to changing food quality and quantity, with a focus on deposit feeding and bioturbation. In: Berger WH, Smetacek FS, Wefer G (eds) Productivity of the ocean: present and past. John Wiley \& Sons, Dahlem, p 235-253

Levin LA (1981) Dispersion, feeding behavior and competition in two spionid polychaetes. J Mar Res 39:99-117

Levin L, Blair N, De Master D, Plaia G, Fornes W, Martin C, Thomas C (1997) Rapid subduction of organic matter by maldanid polychaetes on the North Carolina slope. J Mar Res 55:595-611

Loo LO, Jonsson PR, Sköld M, Karlsson Ö (1996) Passive suspension feeding in Amphiura filiformis (Echinodermata: Ophiuroidea): feeding behaviour in flume flow and potential feeding rate of field populations. Mar Ecol Prog Ser 139:143-155

Nozais C, Duchêne JC, Bhaud M (1997) Control of position in the water column by the larvae of Poecilochaetus serpens (Polychaeta): the importance of mucus secretion. J Exp Mar Biol Ecol 210:91-106

Pearson TH, Rosenberg R (1987) Feast and famine: structuring factors in marine benthic communities. In: Gee JHR, Giller PS (eds) The 27th Symposium of The British Ecological Society Aberystwyth 1986. Blackwell Scientific Publications, Oxford, p 373-395

Rhoads DC (1974) Organism sediment relations on the muddy sea floor. Oceanogr Mar Biol Annu Rev 12: $263-300$

Riisgård HU, Larsen PS (2000) Comparative ecophysiology of active zoobenthic filter feeding, essence of current knowledge. J Sea Res 44:169-193

Rosenberg R, Nilsson HC, Hollertz K, Hellman B (1997) Density-dependent migration in an Amphiura filiformis (Amphiuridae, Echinodermata) infaunal population. Mar Ecol Prog Ser 159:121-131

Rosenfelder AM, Marshall NF (1967) Obtaining large undisturbed and oriented samples in deep waters. In: Richards AF (ed) Marine geotechniques. University of Illinois Press, Chicago, p 243-263

Submitted: December 27, 2000; Accepted: March 29, 2001 Proofs received from author(s): November 19, 2001 